\title{
Coffee, pancreatic cancer, and K-ras mutations: updating the research agenda
}

We very much appreciate the interest of Kuper and colleagues ${ }^{1}$ in our paper, ${ }^{2}$ and we thank them for raising several issues of relevance for research on pancreatic carcinogenesis and for epidemiological thinking on causality.

\section{Risk of pancreatic cancer among heavy coffee drinkers and the "overall" risk} As mentioned in our paper ${ }^{2}$ (Introduction, second paragraph), the epidemiological evidence certainly includes the possibility that the risk of exocrine pancreatic cancer is slightly increased among people drinking large amounts of coffee. This conclusion has been achieved by several reviews of the literature and one meta-analysis. ${ }^{2}$ Figure 1 of Kuper et al is in line with such possibility. How much could "large amounts" be? It is hard to say, mostly because the actual composition of the beverage varies so much across countries, as do probably a number of factors with which coffee interacts to cause the increased risk. Specific studies are needed to clarify these issues, as we shall see immediately.

In principle, the previous sentences are compatible with another conclusion, which we consider fairly well established and that we also share with our colleagues ${ }^{1}$ : the epidemiological evidence indicates that no overall association exists between coffee drinking and risk of exocrine pancreatic cancer (Introduction, second paragraph; Discussion, third paragraph). ${ }^{2}$ In table 1 , we now present adjusted odds ratios for the entire group of 107 cases of pancreatic cancer, as compared with the three referent groups that our original paper mentioned (Discussion, second and third paragraphs). ${ }^{2}$ As can be seen (table 1 , first and second columns), the overall risk estimates are very close to the null value and statistically non-significant. As mentioned in the footnote to table 1, odds ratios compare regular and nonregular coffee drinkers, based on the a priori chosen cut off point of two cups per week - a definition previously used by epidemiological studies in Spain and elsewhere. ${ }^{2}$

None the less, assessing a graphical display of the amount of coffee drunk is warranted, as distributions are skewed, the sample size is relatively small, and a non-dichotomous variable is also of interest. Accordingly, figure 1 shows the average number of cups of coffee per week that each person reported drinking during the year before onset of symptoms or the index date; each dot in the figure corresponds to one subject. The mean for all 105 cases of exocrine pancreatic cancer (13.2 cups/week) is only slightly higher and not statistically significantly different from the mean of any of the referent groups $(p=0.368$ for the difference against cancer of the extrahepatic biliary system, $\mathrm{p}=0.092$ for benign biliary pathology, and $\mathrm{p}=0.839$ for Hospital del Mar controls; Student's $t$ test). The median for the 105 cases ( 14 cups/week) is also somewhat higher than the corresponding values for the referent groups ( $p$ values: 0.496, 0.167, 0.652, respectively; Wilcoxon two sample rank sum test). Therefore, our data are compatible with the judgements we made in the previous two paragraphs.

\section{Risk of K-ras mutation among cases of exocrine pancreatic cancer}

In our study (Discussion, second paragraph), ${ }^{2}$ regular coffee drinkers were similarly common among cases of exocrine pancreatic cancer with a K-ras mutation than among the referent groups, and this finding is now confirmed by the multivariate analyses (table 1, third and fourth columns). By contrast, regular coffee drinkers were less common among cases of exocrine pancreatic cancer without a K-ras mutation than among the referent groups (table 1, fifth and sixth columns).

Certainly, when we look at the mean and median amount of coffee that subjects drank (fig 1), we realise that mutated cases drank slightly larger amounts than referents, although only the comparison against benign biliary pathology is close to statistical significance $(\mathrm{p}=0.028$, Student's $t$ test; $\mathrm{p}=0.052$, Wilcoxon test). By contrast, coffee consumption among wild type (non-mutated) cases was similar or slightly lower than among referents (all $\mathrm{p}$ values $>0.15)$.

What conclusion can then be reached with respect to the direction of the case-case association? (is coffee drinking more common than expected among $\mathrm{K}$-ras mutated cases or, alternatively, is it less common among wild type cases?). It remains to be elucidated. Indeed, the data presented in this paper further emphasise our belief that "as this is the first time that such finding [the coffee and K-ras association] is reported, additional studies are clearly needed to either confirm it or refute it." ${ }^{2}$ This need is not in contradiction with the view-which we share with Kuper et al - that our case-case study was less likely to suffer from selection or information bias than conventional casecontrol studies. ${ }^{1-5}$ By contrast, our case-referent comparisons are imperfect, and were hence given just an ancillary role: to provide clues for what direction the case-case association might have. ${ }^{2-4}$ Independent refutation or replication is needed, for to date ours remains the only study on $\mathrm{K}$-ras mutations in pancreatic cancer with lifestyle and environmental information collected through personal interviews, it is the study with the largest number of cases, and with the earliest and best characterised selection process. $^{2-5}$ It is also the only report on coffee consumption and ras mutations for any human cancer. The prospective

Table 1 Coffee drinking ${ }^{\star}$ and exocrine pancreatic cancer. Risk estimates for cases of pancreatic cancer (all, mutated, non-mutated) compared with three referent groups from the PANKRAS II study $y^{2-8}$

\begin{tabular}{|c|c|c|c|c|c|c|}
\hline \multirow[b]{3}{*}{ Referent group } & \multicolumn{2}{|c|}{ All cases of pancreatic cancer $(n=107)$} & \multirow{2}{*}{\multicolumn{2}{|c|}{$\begin{array}{l}\text { K-ras mutated cases of pancreatic } \\
\text { cancer }(n=83) \\
\text { Adjusted by }\end{array}$}} & \multirow{2}{*}{\multicolumn{2}{|c|}{$\begin{array}{l}\text { Wild type K-ras cases of pancreatic } \\
\text { cancer }(n=24) \\
\text { Adjusted by }\end{array}$}} \\
\hline & \multicolumn{2}{|l|}{ Adjusted by } & & & & \\
\hline & Age, sex & $\begin{array}{l}\text { Age, sex, } \\
\text { smoking, alcohol }\end{array}$ & Age, sex & $\begin{array}{l}\text { Age, sex, } \\
\text { smoking, alcohol }\end{array}$ & Age, sex & $\begin{array}{l}\text { Age, sex, } \\
\text { smoking, alcohol }\end{array}$ \\
\hline Cancer of the extrahepatic biliary system $(n=122)$ & $0.71(0.34,1.51)$ & $0.64(0.29,1.37)$ & $1.00(0.42,2.36)$ & $0.94(0.39,2.28)$ & $0.31(0.11,0.87)$ & $0.24(0.08,0.70)$ \\
\hline Benign biliary pathology $(n=54)$ & $0.80(0.32,2.01)$ & $0.77(0.30,1.97)$ & $1.12(0.40,3.11)$ & $1.11(0.39,3.17)$ & $0.34(0.11,1.10)$ & $0.36(0.11,1.14)$ \\
\hline Hospital del Mar controls $(n=29)$ & $0.82(0.26,2.57)$ & $0.74(0.23,2.39)$ & $1.08(0.32,3.63)$ & $0.97(0.28,3.40)$ & $0.36(0.09,1.51)$ & $0.34(0.08,1.49)$ \\
\hline
\end{tabular}

${ }^{\star}$ Regular coffee drinkers compared with non-regular coffee drinkers. Values are odds ratios and their $95 \%$ confidence intervals. 

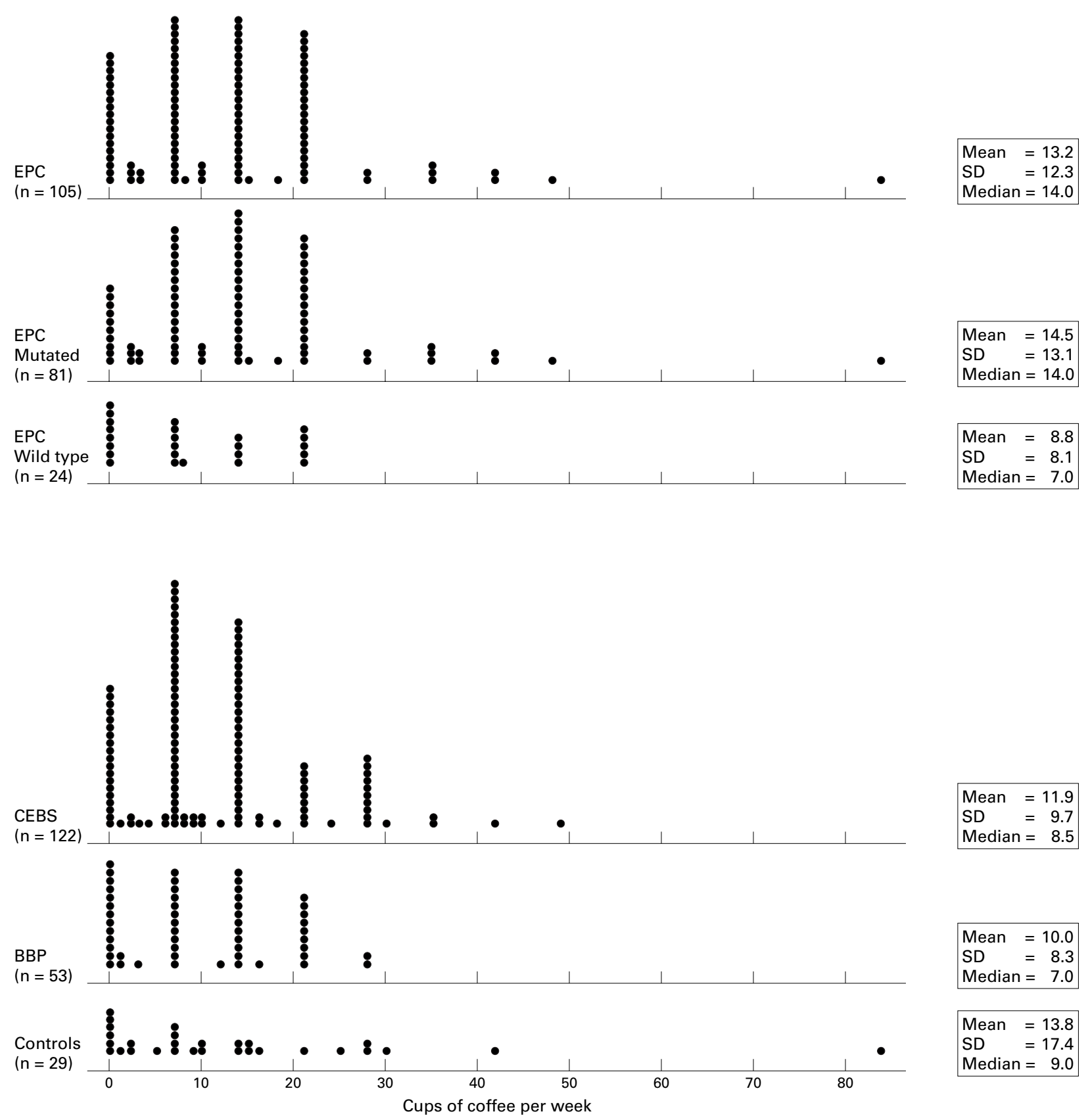

Mean $=13.8$

$\mathrm{SD} \quad=17.4$

Median $=9.0$

Figure 1 Consumption of coffee among cases of exocrine pancreatic cancer (EPC) and among referents with cancer of the extrahepatic biliary system $(C E B S)$, benign biliary pathologies (BBP), and controls from Hospital del Mar. Information on amount of coffee was missing for two cases of EPC.

collection of clinical, tumoural and biochemical data, the excellent case ascertainment and response, and its quality assurance procedures are important features of the study, but it is not without limitations. ${ }^{2-8}$

\section{Smoking and other interactions}

The paper by Kuper and colleagues raises still other points that we would like to briefly discuss. Certainly, no study can ever completely exclude residual confounding by smoking, especially if subjects' reports are not totally accurate. However, smoking was more common in the wild type group, ${ }^{2}$ and better adjustment for smoking - if at all possible or necessary - would further strengthen the association between coffee and K-ras mutations because of "negative confounding". 9 Detailed information was available on tobacco and alcohol consumption for each period of life, including changes in the type and amount of products.
Adjustment by alternative measures of smoking and alcohol did not materially change the association with coffee; some additional models are summarised in table 2 .

Our colleagues ${ }^{1}$ also rightly ask whether "an interaction between coffee and an unknown factor (smoking?)" could cause exocrine pancreatic cancer. Firstly, we wonder whether epidemiological and clinical findings on this interaction have been sought as intensively as they deserve, given the strong evidence that tobacco and coffee constituents interact in many biological systems. ${ }^{10-15}$ Secondly, as mentioned in our paper, the association between coffee and K-ras was somewhat stronger among men, among ever-smokers, and among subjects less than 60 years old ${ }^{2}$; the corresponding $\mathrm{p}$ values for the interactions of coffee with sex, smoking and age are $0.434,0.529$ and 0.173 , respectively. Remarkably, odds ratios are above 6 and 19 in some subgroups (table 2). With multiple comparisons, 
Table 2 The association between K-ras mutations and regular coffee drinking, adjusted by alternative measures of tobacco and alcohol consumption *

\begin{tabular}{llll}
\hline Model / subjects & Number & Odds ratio $(95 \%$ CI) & p Valuet \\
\hline 1 All & 107 & $5.41(1.64,17.78)$ & 0.005 \\
2 All & 107 & $4.13(1.34,12.70)$ & 0.013 \\
3 All & 101 & $5.49(1.68,17.95)$ & 0.005 \\
4 All & 93 & $4.59(1.28,16.51)$ & 0.019 \\
5 All & 107 & $4.46(1.42,13.98)$ & 0.010 \\
6 Male smokers & 54 & $6.18(1.31,29.18)$ & 0.022 \\
7 Ever alcohol drinkers & 89 & $4.01(1.22,13.17)$ & 0.022 \\
8 All subjects <60 years old & 39 & $19.06(1.38,262.9)$ & 0.028 \\
\hline
\end{tabular}

*All models are sex and age adjusted (except models 6 and 8 ). Model 1: smoking as cumulative number of years smoked, alcohol in five categories (non-drinker, occasional, low consumption, high consumption, heavy drinker). Model 2: smoking as ever/never, alcohol in five categories. Model 3: number of years smoked, number of years of alcohol drinking. Model 4: cumulative lifetime number of cigarettes, cumulative lifetime grams of alcohol. Models 5 and 8: cumulative lifetime number of cigarettes, alcohol in five categories. Model 6: ever smokers. Model 7: smoking as ever/never, years of alcohol drinking. Only seven women had ever smoked, and only seven men were never-smokers. †Value for regular coffee drinking derived from the corresponding regression coefficient in the logistic model.

false positives are a clear possibility, whereas the low statistical power to detect interactions is also a problem. Only large studies may clarify these issues. ${ }^{16}$

Much of the evidence discussed in this paper constitutes or reflects reasons to study the role of interactions between coffee and other lifestyle, environmental and genetic factors in the pathogenesis of exocrine pancreatic cancer. ${ }^{1-41617}$ Firstly, conceptually, "coffee could play a modulating role in a subgroup of patients with pancreatic cancer, an effect that would be diluted in the entire population of subjects with the disease."2 Secondly, the potential increased risk at higher levels of consumption is also compatible with several types of interaction. Thirdly, empirically, every now and then a new study again reports an increased risk of developing exocrine pancreatic cancer at moderate levels of coffee consumption: such consumption could have an effect only among population groups with specific environmental or genetic characteristics. Fourthly, notwithstanding methodological issues, the vast heterogeneity in results from different studies-that span from significant protection against to significant risk for pancreatic cancer at universally popular levels of coffee consumption - is another reason to suspect that such estimates result from different interactions among different "component causes". And fifthly, strengthening the previous statements, there is ample proof that many constituents of coffee-notably but not solely, caffeine-exert strong effects upon a wide variety of physiological, cellular and molecular systems. ${ }^{210-23}$ Such biological evidence is in sharp contrast with the paucity of epidemiological studies treating coffee as an effect modifier.

Of course, some of the reported associations -including coffee and K-ras activation - might totally or partly reflect the indirect action of factors with which coffee drinking is associated in a biologically irrelevant fashion. ${ }^{24}$

In any case, a central fact is that-over 10 years after their high prevalence at diagnosis was first reported-point mutations in the K-ras gene remain the most consistent genetic alteration in exocrine pancreatic cancer. Yet, evidence in support of the hypothesis that the occurrence or persistence of these mutations may be related to some type of environmental factors has been elusive, probably for lack of appropriate studies. ${ }^{4}$

From a mechanistic-biological perspective, the study of interactions between methylxanthine containing beverages and environmental agents in well defined groups of people, based on sound epidemiological reasoning, could yield new insights into several processes important in cancer aetiology, such as cell cycle checkpoints, signal transduc- tion, genomic stress, DNA repair, apoptosis, drug resistance, and metabolic polymorphisms. Innovative epidemiological studies could hence yield biologically relevant knowledge..$^{25-28}$ Perhaps this is why our paper ${ }^{2}$ caught the eye of Nature, ${ }^{17}$ where it was said to "follow recent but intriguing results thrown up by rodent and cell culture research about the effects of caffeine and coffee."

We agree with Kuper and colleagues ${ }^{1}$ that interactions can be viewed as part of the broader causal process, rather than as simply modifying the role of a "cause" in a subgroup of the population; consequently, coffee drinking can indeed be conceptualised as a "component cause, however minor"1 or however indirect. Our colleagues scrupulously portray our belief that great caution is warranted with our findings, ${ }^{2}$ as is always the case with a new gene-environment interaction. Nevertheless, it is perhaps a bit of an exaggeration to state that we did not "consider causality as plausible". What we consider less probable is a direct causal effect of coffee on K-ras activation; but we would not be surprised if indirect causal effects were unveiled in the future.

From the clinical and public health perspectives, what implications could the interactions have? In this and other areas of research on coffee interactions, practical recommendations can rarely be made before basic biological knowledge is firmly established. Particularly if smoking is involved. ${ }^{10-152930}$ We therefore also concur that the association we reported has yet limited practical implications, and is probably more remarkable from a mechanistic or pathogenic angle than from a public health point of view. ${ }^{2}$ At least for now, given our current limited and fragmentary available knowledge. Certainly, more evidence needs to be accrued ${ }^{1-4}{ }^{16}$; but more importantly, very diverse bodies of evidence need to be connected. ${ }^{25} 28$ Molecular epidemiology could help integrate patchy findings and theoretical considerations on causality. ${ }^{916}{ }^{16}$ More specific and innovative hypotheses on pancreatic pathogenesis could thus be tackled. And the new research agenda would take off.

MIQUEL PORTA NÚRIA MALATS JUAN ALGUACIL LAURA RUIZ MANUEL JARIOD ALFREDO CARRATO JULI RIFÁ LUISA GUARNER

Institut Municipal d'Investigació Mèdica (IMIM), Carrer del Dr Aiguader 80, E-08003 Barcelona, Spain

The authors gratefully acknowledge the many contributions of all other members of the PANKRAS II Study.

Funding: FIS (grant 95/0017) and CIRIT (1999 SGR 00241).

1 Kuper HE, Mucci LA, Trichopoulos D. Coffee, pancreatic cancer and the question of causation. 7 Epidemiol Community Health 2000;54:650-1.

2 Porta M, Malats N, Guarner L, et al. Association between coffee drinking and K-ras mutations in exocrine pancreatic cancer. $\mathcal{F}$ Epidemiol Community Health 1999:53:702-9.

3 Porta M, Malats N, Jariod M, et al. Serum concentrations of organochlorine compounds and K-ras mutations in exocrine pancreatic cancer. Lancet 1999;354:2125-29.

4 Porta M, Jariod M, Malats N, et al. Prevalence of K-ras mutations at diagnosis and serum levels of DDT, DDE, PCBs and other organochlorine compounds in exocrine pancreatic cancer. In: Gress T, ed. Molecular pathogenesis of pancreatic cancer. Amsterdam: IOS Press, 2000:35-42.

5 Porta M, Costafreda S, Malats N, et al. Validity of the hospital discharge diagnosis in epidemiologic studies of biliopancreatic pathology. Eur F Epidemiol (in press)

6 Soler M, Malats N, Porta M, et al. Medical conditions in patients with pancreatic and biliary diseases: Validity and agreement between data from questionnaires and medical records. Dig Dis Sci 1999;44:2469-77.

7 Alguacil J, Kauppinen T, Porta M, et al. Risk of pancreatic cancer and occupation , Kauppinen T, Porta M, et al. Risk of pan:44:391

8 Alguacil J, Porta M, Benavides FG, et al. Occupation and pancreatic cancer in Spain: a case-control study based on job titles. Int $\mathcal{f}$ Epidemiol (in press). 9 Maguire A, Porta M, Piñol JL, et al. Reproductive factors and breast cancer. Am f Epidemiol 1994;140:658-59. 
10 Carrillo JA, Benitez J. Caffeine metabolism in a healthy Spanish population: $\mathrm{N}$-acetylator phenotype and oxidation pathways. Clin Pharmacol Ther

11 Kawamoto T, Yoshikawa M, Matsuno K, et al. Effect of side-stream cigarette smoke on the hepatic cytochrome P450. Arch Environ Contam Toxicol 1993; 25:255-9.

12 Vistisen K, Poulsen HE, Loft S. Foreign compound metabolism capacity in man measur

13 Yang M, Kawamoto T, Katoh T, et al. Effects of lifestyle and genetic polymorphisms on consumption of coffee or black tea and urinary caffeine levels. Biomarkers 1998;3:367-77

14 López-Abente G, Escolar A. Coffee drinking modifies the increase in bladder cancer risk caused by smoking. F Epidemiol Community Health (in press).

15 Slattery ML, Caan BJ, Anderson KE, et al. Intake of fluids and methylxanthine-containing beverages: association with colon cancer. Int $\mathcal{F}$ Cancer 1999;81:199-204.

16 Vineis P. ras Mutations and a cup of coffee: cause, confounder, effect modification, or what else? f Epidemiol Community Health 1999;53:685.

17 Abdulla S. Science update: Mocha and mutations. Nature [on-line] 1999 December 15. Available from: URL: http://helix.nature.com/nsu/991216/ 991216-9.html [last accessed 27 June 2000]

18 Kihlman BA Caffeine and chromosomes. Amsterdam: Elsevier, 1977.

19 Spiller GA, ed. Caffeine. Boca Ratón: CRC, 1998.

20 Rowley R. Mammalian cell-cycle responses to DNA-damaging agents. In: Nickoloff JA, Hoekstra MF, eds. DNA damage and repair. Vol. II: DNA repair in higher eukaryotes. Totowa, New Jersey: Humana Press, 1998:465-86.
21 Shackelford RE, Kaufmann WK, Paules RS. Cell cycle control, checkpoint mechanisms, and genotoxic stress. Environ Health Perspect 1999;107 (suppl

22 Kohlmeier L, DeMarini D, Piegorsch W. Gene-nutrient interactions in nutritional epidemiology. In: Margetts BM, Nelson M, eds. Design concepts in nutritional epidemiology. Oxford: Oxford University Press, 1997:312-37. 23 Conlay LA, Conant JA, deBros F, et al. Caffeine alters plasma adenosine levels. Nature 1997;389:136.

24 Schreiber GB, Robins M, Maffeo CE, et al. Confounders contributing to the reported associations of coffee or caffeine with disease. Prev Med 1988;17: 295-309.

25 Porta M, Alvarez-Dardet C. Epidemiology: bridges over (and across) roaring levels. F Epidemiol Community Health 1998;52:605.

26 Porta M. Epidemiological plausibility. Re.: "Biologic plausibility in causal Porta 18.

27 Porta M, Ashton JR, Álvarez-Dardet C. Genes as causes: scientific fact or simplistic thinking? F Epidemiol Community Health 1999;53:385.

28 Porta M, Alvarez-Dardet C. How is causal inference practised in the biological sciences?. F Epidemiol Community Health 2000;54:559-60.

29 Kuper H, Tzonou A, Kaklamani E, et al. Tobacco smoking, alcohol and coffee consumption and their interaction in the causation of hepatocellular carcinoma. Int 7 Cancer 2000;85:498-502.

30 Malats N, Porta M, Corominas JM, et al. Ki-ras mutations in exocrine pancreatic cancer: association with clinico-pathological characteristics, and with tobacco and alcohol consumption. Int f Cancer 1997;70:661-7.

31 Robins JM, Hernán MA, Brumback B. Marginal structural models and causal inference in epidemiology. Epidemiology (in press). 